\title{
Programa de Orientação Breve a Cuidadores de bebês: avaliação e formulação
}

Programa de Orientación Breve a Cuidadores de bebés: evaluación y formulación Brief Guidance Program for Baby Caregivers: Assessment and Formulation

Pâmella Batista de Souza Universidade Federal de Santa Catarina - Santa Catarina - Brasil

\author{
Ana Priscila Batista \\ Universidade Estadual do Centro-Oeste - Paraná - Brasil
}

Caroline Guisantes de Salvo Toni

Universidade Estadual do Centro-Oeste-Paraná - Brasil

\section{RESUMO}

Atualmente programas de Promoção e Prevenção têm ganhado espaço na área da saúde. Um desses programas é o Cuida-Bem, criado e realizado em uma universidade pública do Paraná-Brasil, que atua com pais e cuidadores de bebês por meio da psicoeducação de temas como a interação positiva ecuidador-bebê, desenvolvimento infantil, prevenção de maus-tratos infantis e Síndrome do Bebê Sacudido (SBS). Esse artigo buscou descrever dois momentos do programa: sua formulação e a avaliação dos resultados de sua implementação, portanto, seu método, resultados e discussão apresentam estes dois momentos. A metodologia utilizada foi de abordagem qualitativa e quantitativa, do tipo exploratório com realização de intervenção, teste piloto e avaliação. Os resultados mostram que referente à formulação do programa, esta se deu em etapas. São exemplos de facilidades desse processo o acesso aos participantes e de dificuldades a necessidade de buscar por diferentes formatos de realização da orientação breve. Referente a avaliação foi observado que os participantes obtiveram aumento de conhecimento dos temas tratados no programa, uma vez que os relatos demonstram um acréscimo de conhecimentos, sobretudo, no tema SBS. Conclui-se que na formulação e execução de programas preventivos e de promoção é fundamental o respaldo teórico e técnico, bem como a sequência de etapas sugeridas pela literatura da área que auxiliam na sua melhor organização, conclui-se também que a etapa de avaliação é fundamental, pois possibilita acrescimentos às características do programa. Por fim, por meio desse relato de experiência, evidencia-se a possibilidade de realizar iniciativas de extensão universitária embasada cientificamente.

Palavras-Chave: Programas Preventivos. Interação Cuidador - Bebê. Síndrome do Bebê Sacudido. 


\title{
RESUMEN
}

Actualmente programas de Promoción y Prevención han ganado espacio en el área de la salud. En el caso de los padres, los padres y los cuidadores de los bebés a través de la psicoeducación de temas como la interacción positiva ecuador-bebé, el desarrollo infantil, la prevención de malos tratos, tratos infantiles y Síndrome del Bebé Sacudido (SBS). Este artículo buscó describir dos momentos del programa: su formulación y la evaluación de los resultados de su implementación, por lo tanto, su método, resultados y discusión presenta estos dos momentos. La metodología utilizada fue de abordaje cualitativo y cuantitativo, del tipo exploratorio con realización de intervención, prueba piloto y evaluación. Los resultados muestran que referente a la formulación, ésta se dio en etapas, son ejemplos de facilidades de ese proceso el acceso a los participantes y de dificultades la necesidad de buscar por diferentes formatos de realización de la orientación breve. En la evaluación se observó que los participantes obtuvieron un aumento de conocimiento de los temas tratados en el programa, ya que los relatos demuestran un aumento de conocimientos, sobre todo, en el tema SBS. Se concluye que en la formulación y ejecución de programas preventivos y de promoción es fundamental el respaldo teórico y técnico, así como la secuencia de etapas sugeridas por la literatura del área que auxilian en su mejor organización, se concluye también que la etapa de evaluación es fundamental, pues permite añadir a las características del programa. Por último, a través de este relato de experiencia, se evidencia la posibilidad de realizar iniciativas de extensión universitaria basadas científicamente.

Palabras-clave: Programas Preventivos. Interacción Cuidador - Bebé. Síndrome del Bebé Sacudido.

\begin{abstract}
Currently, the programs of Promotion and Prevention have gained space in the health area. One of these programs is Care-Well, created and carried out at a public university in Paraná-Brazil, which works with parents and caregivers of babies through the psychotherapy of topics such as childpositive interaction, child development, treatment and Vaulted Baby Syndrome SBS). This article sought to describe two moments of the program: its formulation and the evaluation of the results of its implementation, so its method, results and discussion present these two moments. The methodology used was qualitative and quantitative, of the exploratory type with intervention, pilot test and evaluation. The results show that, regarding the formulation of the program, this was done in stages. Some of examples of facilities of this process access to participants and difficulties the need to look for different short guidance formats. Regarding the evaluation, it was observed that the participants obtained an increase in the knowledge of the topics treated in the program, since the reports show an increase of the knowledge, especially in the subject SBS. The conclusion evidentiates that in the formulation and execution of prevention and promotion programs, the theoretical and technical support, as well as the sequence of steps suggested by the literature of the area that helps in its better organization, are fundamental, it is also concluded that The phase is because it allows additions to the characteristics of the program. Finally, through this report of experience, it is evident the possibility of carrying out university extension initiatives scientifically.
\end{abstract}

Keywords: Preventive Programs. Caregiver Interaction - Baby. Shaken Baby Syndrome.

Introdução

A Organização Mundial da Saúde OMS (2001) destaca que trabalhar com
Prevenção é atuar sobre fatores de risco, sendo geralmente realizada em períodos curtos de tempo. Ainda, conforme a OMS, a prevenção é a evitação de que algum dano ocorra e deve

PSI UNISC, Santa Cruz do Sul, Vol. 2, n. 1,jan./jun. 2018, p.<106-121>. 
estar atrelada à promoção da saúde e do bemestar. Pereira e Dittrich (2007, p. 232) afirmam que "as intervenções preventivas se focalizam em diminuir os fatores de risco e em aumentar os fatores de proteção". Ou seja, atuar em prevenção é ainda promover saúde a partir do trabalho realizado em instâncias que abarcam fatores sociais, culturais e biológicos. Berlinguer (1994) cita dois aspectos interessantes que a prevenção possibilita: a virtude antecipatória, isto é, se pode intervir para evitar algo, e o princípio de universalidade, válido para medidas de prevenção universais e que oferece acesso igualitário a todos. Também cabe mencionar que as medidas de prevenção podem ser seletivas para determinados grupos em situação de risco, ou podem ser individualizadas caso a caso.

Já a Promoção concentra-se "no desenvolvimento de desfechos positivos, como vínculos afetivos e sociais, bem-estar e qualidade de vida" (Murta et al, 2015, p. 68). Por enfatizar aspectos positivos de diferentes questões pode evitar a ocorrência de situações e consequências consideradas negativas, sendo que é a primeira questão citada que define o que é promoção.

Prevenção e Promoção se diferem em pressupostos teóricos e práticos, porém, podem se complementar e ter aproximações. Ao buscar impedir determinados males, a Prevenção promove fatores que são protetivos e a Promoção, por sua vez, ao almejar fortalecer desfechos que são positivos faz isto também prevenindo diferentes tipos de danos (Berlinguer, 1994; Murta et al, 2015).

Em decorrência disto, também as intervenções podem ter um cunho tanto de Promoção quanto de Prevenção, tendo, portanto, a mesma base e com metas diferentes. Essas duas iniciativas geram contribuições para a esfera social, trazendo benefícios para a comunidade atendida, conforme afirmado por Murta et al (2015). Assim, os programas que tem como base a Promoção e Prevenção podem adquirir diferentes formatos e buscar atingir diferentes objetivos e segmentos. Uma dessas possibilidades volta-se à responder às necessidades de crianças e seus cuidadores por meio de um conjunto de serviços, apoios e recursos, este formato de intervenção em promoção e prevenção vem sendo indicados com muita frequência na literatura (Lohr et al, 2007).

Estes programas possuem benefícios a curto e em longo prazo, e somam-se a formas de Prevenção e Promoção da saúde. Este é um campo para o qual a Psicologia tem se voltado nos últimos tempos, buscando orientar e auxiliar em problemas já existentes e prevenir outros que possam vir a se desenvolver (Lohr et al, 2007).

Uma das possibilidades de execução de programas preventivos é através da extensão universitária. Conforme Botomé (1996), a extensão forma o tripé da universidade junto ao ensino e à pesquisa e atua como possibilidade de aprendizado prático para os alunos e de prestação de serviços à comunidade. Diversas pesquisas da área da Psicologia, como as feitas por Chaves, Melo e Ferreira (2010), Muller, Paul e Santos (2008) e Williams e Habigzand (2014) relatam experiências sobre o trabalho de prevenção realizado a partir de experiências universitárias.

Concebendo a possibilidade de atuar em Prevenção através da extensão universitária, criou-se o Projeto Cuida-Bem. Este projeto, realizado através de orientações breves a cuidadores, aborda temas sobre interação cuidador-bebê, prevenção de maustratos infantis, Síndrome do Bebê Sacudido (SBS) e aspectos psicológicos, cognitivos, motores, afetivos e sociais do desenvolvimento infantil.

Graça (2010) e Weber (2008) são algumas autoras que destacam o quanto as atitudes dos cuidadores interferem no desenvolvimento infantil, pois, o desenvolvimento da criança está diretamente relacionado com as práticas educativas de seus cuidadores, havendo consenso na literatura 
quanto a isso (Baumrind, 1966; Gomide 2006; Pelaez \& Novak, 2004; Pinheiro \&Haase, 2012; Weber, 2008). Isso é ainda mais importante nos primeiros meses de vida considerando que "o bebê passa a maior parte do seu tempo inicial de vida com a família" (Graça et al, 2010, p. 179). Além disto, o bebê possui recursos limitados, fragilidade $\mathrm{e}$ nenhuma autonomia, portanto, os cuidadores precisam reagir às suas necessidades (Bee, 1996). Por esses mesmos motivos, a figura do cuidador e o cuidado parental recebem importância, pois, eles são preditores do desenvolvimento e bem-estar do bebê, promovendo sua interação e possibilitando seu desenvolvimento em diversas instâncias (Gil, Oliveira \&Souza, 2012; Graça, 2010).

No entanto, a interação entre cuidadores e bebês pode ocorrer tanto de maneira positiva quanto negativa. Com relação à maneira negativa, esta ocorre por meio de atitudes que podem maltratar a criança de forma física ou psicológica ou mesmo ausência de atitudes, sinalizando negligência. Williams e Maia (2005) afirmam que tais atitudes podem decorrer em função de um déficit de habilidades parentais, como expressão de afeto, envolvimento, além de uso de ações coercitivas. Isso reflete, possivelmente, em um déficit também na interação com os filhos e no desenvolvimento da criança, e são vistas como um fator de risco ou atraso no desenvolvimento da criança.

Um exemplo de habilidade inadequada é o Abuso Físico. No entanto, em âmbito nacional, o Estatuto da Criança e do Adolescente assinala que as crianças devem ser protegidas e que qualquer forma de violência contra elas deve ser repreendida, destaca ainda em seu Art. $5^{\circ}$ que "nenhuma criança ou adolescente será objeto de qualquer forma de negligência, discriminação, exploração, violência, crueldade e opressão, punido na forma da lei qualquer atentado, por ação ou omissão, aos seus direitos fundamentais" (Brasil, 1990, s/p). Mas, sabese que na realidade a violência ainda é presente e se expressa de diferentes formas.
Segundo o Ministério da Saúde (2001) uma das formas de maus-tratos infantil é a SBS. Essa síndrome é causada em decorrência da criança ter sido forte, exageradamente e intencionalmente balançada para frente e para trás, ao ser segurada pelo tórax, o que pode acarretar em diversos tipos de danos (Lopes, 2013). São encontrados na literatura diversos termos para designar essa forma de maus tratos, tais como síndrome do bebê sacudido, trauma craniano abusivo, trauma craniano não-acidental, trauma craniano violento ou trauma craniano infligido, o que demonstra ausência de definição terminológica a respeito do assunto. Devido a este motivo, optou-se por utilizar apenas o termo SBS neste trabalho (e nas intervenções realizadas no programa), por ter sido esta terminologia utilizada nas atividades do programa descrito, visto que este termo é mais dissociado da medicina e mais próximo da linguagem de senso comum.

Em termos históricos, os estudos sobre esse tipo de violência infantil surgiram em 1962 com Kempe e outros pesquisadores (Kempe et al, 1985). Estes pesquisadores chamavam a atenção para possíveis maustratos que cuidadores poderiam causar a seus bebês e a necessidade de conscientização sobre movimentos e sacudidas violentas e repetitivas, que podem levar à SBS.

Atualmente se reconhece que há alguns fatores de risco que podem aumentar a probabilidade de ocorrência da SBS, podendo tais fatores serem vistos a partir de três grupos: 1) respectivos aos cuidadores: serem menores de 18 anos, famílias monoparentais, mães com baixo grau de escolaridade e que não fizeram o acompanhamento pré-natal, além de questões como falta de conhecimento sobre desenvolvimento infantil e padrão de choro, além de baixa tolerância à frustração; 2) respectivos ao bebê: ser menor de um ano de idade, do sexo masculino e ter nascido de forma prematura ou com peso abaixo da média; e 3) respectivas à situação: momentos de estresse, status socioeconômico familiar, dificuldades da gestação, entre outros (Hennes, Kini; Palusci 2001). No entanto, o fator que mais prevalece como desencadeante 
da ocorrência da SBS é o choro incontrolável do bebê, que pode provar desequilíbrio emocional, irritação, exaustão e impotência a cuidadores que já possuem algum fator de risco listado anteriormente (Kempe et al, 1985; Lopes, 2013).

Os sintomas do bebê que foi sacudido são vários, desde vômitos, crises convulsivas, apatia, falta de apetite, hemorragias na retina, lesões oculares, deficiência física e auditiva, fraturas em ossos, dificuldades de aprendizagem, paralisia cerebral, parada cardíaca e até morte (Cardoso et al, 2003; Ministério da Saúde, 2001). No entanto, embora de uma incidência significativa, no Brasil a SBS é pouca estudada e também possui poucas iniciativas que visam preveni-la (Lopes, 2013).

Além disto, também os Programas de Intervenção Precoce são escassos no Brasil (Foley et al 2013), entretanto, é de suma importância em termos sociais a efetivação dos mesmos. Segundo Marinho (2000), as iniciativas que visam desenvolver programas deste cunho promovem contribuições para a esfera social, trazendo benefícios para a comunidade local e de abrangência do programa. Dessa forma, a importância e relevância social de programas desta natureza sustentaram e justificaram a realização da presente pesquisa. Além disso, com relação a avaliação, considerou-se a afirmativa de Lopes (2013), sobre a importância de que programas preventivos sejam avaliados em sua efetividade.

Assim, a justificativa da criação do projeto relatado neste artigo pauta-se na possibilidade de poder contribuir para reverter o quadro citado anteriormente e também se embasa na afirmação de Lohr et al (2007) e de Lopes (2013) de que é necessário conhecer variáveis que induzem problemas comportamentais de cuidadores que podem interferir no desenvolvimento saudável de seus filhos, e intervir sobre elas a partir de práticas de promoção da saúde e prevenção de doenças. Estes programas se concretizam por meio da oferta de treinamento de habilidades positivas para lidar com os filhos, além do repasse de informações a respeito do Desenvolvimento Infantil, Prevenção à Maus Tratos, entre outros temas.

Segundo Murta e Santos (2015), baseadas em pressupostos da ciência preventiva, é indicado que práticas pautadas em promoção da saúde e prevenção de doenças sigam em sua elaboração algumas etapas pré-definidas, que são: 1- realizar um estudo preparatório sobre o tema e a intervenção, 2- construir a intervenção propriamente dita e 3- última fase, realizar o que é chamado de Teste Piloto, a fim de observar o que é necessário refazer ou readequar para efetivar a atividade em questão. Em comum acordo com essa importante informação da literatura, o projeto descrito nesse artigo seguiu as etapas elucidadas pelas autoras a fim de obter maior potencial.

Coerente a isto, o objetivo do presente artigo é apresentar e descrever a formulação do projeto Cuida-Bem, em suas etapas e detalhamentos, bem como os resultados de sua implementação. Destaca-se que sua construção se pautou nos pilares da Ciência Preventiva e pelas características da extensão universitária.

\section{Método}

Essa subseção está descrita de forma a apresentar os aspectos metodológicos das duas etapas do programa que esse artigo trata, sendo elas 1) referente a formulação do programa e 2) sobre avaliação do programa.

\section{Formulação do Programa}

\section{Procedimentos}

Buscou-se seguir cada uma das três etapas sugeridas por Murta e Santos (2015), a saber:

1- Estudo preparatório sobre o tema e possibilidades de construção da intervenção: levantamento de referências bibliográficas e materiais sobre os temas a serem abordados na orientação a pais; 
2- A organização da intervenção propriamente dita: organização do formato da intervenção e preparação do material ilustrativo;

3- Teste Piloto: foram conduzidas 50 orientações a pais e cuidadores. Ao longo da execução das orientações era observado as estratégias e materiais que compunham as próprias orientações, também eram realizadas discussões entre as equipes sobre cada orientação. Assim, os dados coletados no Teste Piloto também foram utilizados para a avaliação do programa.

\section{Instrumentos}

Cartilha: foi confeccionada previamente pelas autoras em termos de conteúdo, desenhos ilustrativos e layout. Os conteúdos eram sobre aspectos importantes do desenvolvimento infantil, orientações para uma interação positiva entre cuidador-bebê, tipos de choro, além de estratégias para lidar com o choro incessante e prevenir a Síndrome do Bebê Sacudido.

Roteiro de Orientação: as sessões tinham roteiros prévios que previam primeiramente a acolhida da paciente no local da orientação, por segundo explicação sobre o programa, objetivos e forma de participação, por terceiro a orientação propriamente dita em que eram tratados dos temas: desenvolvimento infantil, prevenção de maus-tratos infantis e Síndrome do Bebê Sacudido e por quarto e último momento, era solicitado a/ao participante se haviam dúvidas e então concluído o momento de orientação.

Outros: computadores, para visualizar com os participantes vídeos e panfletos; vídeos-online, com conteúdo similares aos das orientações e visualizados com os participantes sendo eles: "Responding to a Crying Baby", desenvolvido pela equipe do programa de prevenção da Síndrome do Bebê do Hospital da Criança de Westmead, Austrália, traduzido para o português e disponibilizado no site do Laboratório de Análise e Prevenção da Violência da Universidade Federal de São Carlos (2009) e vídeo em que Rafaela Rosa, especialista em linguagem de bebês, fala a respeito dos 5 tipos de choro, a partir de um método proposto por Dustan (2015); e o panfleto-online, intitulado "Não marque bobeira, sacudir o bebê é a maior asneira" também confeccionado pelo laboratório acima mencionado (2009).

\section{Avaliação do programa}

A partir da formulação do programa Cuida-Bem e de sua implementação, conduziu-se a pesquisa de avaliação dos resultados qualitativos do programa.

\section{Local}

O programa Cuida-Bem é realizado em uma Clínica-escola de Psicologia e Fonoaudiologia, que funciona como um espaço para prestação de serviços à comunidade. Dentre o rol de serviços está o Teste da Orelhinha (TOIR) realizado por estagiárias do curso de Fonoaudiologia. O TOIR é realizado na clínica-escola desde 2007 e atende participantes de oito municípios da região em que está localizada.

Como diariamente há uma determinada fila e ordem de bebês para realização do teste e como a clínica atende diversos municípios, alguns dos cuidadores deslocam-se até a clínica e permanecem ali por algum tempo até a conclusão do teste e deslocamento de volta ao seu local de origem. Mesmo outros cuidadores que são residentes do município onde a clínica está situada, aguardam por determinado momento até a realização do teste em seus bebês. Este fator - tempo de espera favoreceu a implementação do programa.

O programa também foi divulgado a sociedade em geral, por meio de panfletos distribuídos em instituições como hospital, Centros de Referência em Assistência Social, ambulatórios, Unidades Básicas de Atendimentos, entre outros.

\section{Participantes}

A população atendida pelo programa no período do segundo semestre de 2014 ao primeiro semestre de 2015 foi de 50 pais e 
cuidadores. Os participantes eram de ambos os sexos, com idade variada a partir dos 13 anos até 54 anos, relembrando que eram tantos cuidadores principais (pais e mães) como também secundários (avós, tios, entre outros).

Do total de participantes, cinco cuidadores compuseram a amostra da pesquisa para responderem as duas entrevistas, os participantes foram escolhidos por conveniência e eram todos do sexo feminino, com idades entre 23 a 35 anos.

\section{Instrumentos}

Foram utilizadas duas entrevistas, estas foram confeccionadas pelas autoras e aplicadas antes e após os cuidadores terem participado do momento de orientação, com o objetivo de compreender se os participantes haviam obtido ganho de conhecimento sobre os assuntos da orientação breve. Portanto, os temas abordados nas entrevistas eram sobre o grau de conhecimento do participante sobre os assuntos das orientações. Para ter melhor flexibilidade de aplicação, o roteiro de perguntas era semiestruturado.

\section{Coleta de dados}

Ao aceitar participar do programa, o cuidador foi convidado a participar também da pesquisa de avaliação do programa, mediante explicação de qual seria a forma de envolvimento na pesquisa. Ao declarar o aceite o cuidador recebia o Termo de Consentimento Livre e Esclarecido (TCLE) e deveria ler as informações e caso concordasse com todas elas, assinar o documento. O TCLE possuía descritas todas as informações relevantes sobre a pesquisa: sua natureza e seus objetivos, possíveis riscos e desconfortos, anonimato, gratuidade e explicação dos procedimentos para a participação da mesma, que consistia em: responder os questionários e, em alguns casos, as entrevistas. Assim, a coleta de dados foi realizada por meio da aplicação da entrevista um e dois a cinco participantes.

Somente após a leitura e assinatura do TCLE por parte dos participantes, foi dado início a coleta de dados, que ocorreu entre a segunda semana de setembro e a segunda semana de dezembro de 2015, geralmente de forma individual, no formato mãe e pesquisadora; mãe, cuidador e pesquisadora; mãe, acompanhante (que geralmente era a figura de avó, tia ou madrinha do bebê) e pesquisadora. No entanto, os acompanhantes poderiam participar do atendimento, mas não da pesquisa. Os participantes respondiam as perguntas da entrevistadora - que também era a aplicadora do programa. Também era certificado de que os participantes não possuíam nenhuma dúvida e, ainda assim, as pesquisadoras permaneceram à disposição para eventuais dúvidas.

As entrevistas foram realizadas em dois momentos pelo seguinte motivo: antes do momento da orientação, objetivando obter informações sobre o conhecimento dos participantes sobre os assuntos tratados e o segundo momento de aplicação do questionário, logo após a orientação. O objetivo era comparar as repostas dos participantes as mesmas questões e assim compreender as contribuições das orientações.

Sobre a entrevista, cabe ressaltar que a mesma foi gravada, mediante aprovação deste aspecto por parte do participante, e posteriormente foram transcritas pelas pesquisadoras. A orientação durava em torno de 30 minutos, acrescido do tempo da realização da entrevista que teve um tempo médio de 10 minutos, assim, ao total, a duração da participação dos cuidadores e pais era de 40 minutos em média.

A análise de dados referente à Avaliação do programa adotou os referenciais e procedimentos de Análise de Conteúdo. A Análise do Conteúdo é uma teoria e método proposto por Bardin (2011) e que atualmente é bastante utilizado em pesquisas da área da Saúde. De forma geral esse método visa analisar e dar significado aos dados acatados. Segundo Campos (2004), o agrupamento das análises pode ser realizado através da criação de categorias de conteúdo, que podem ser estabelecidas a partir da frequência com que o 
conteúdo aparece ou pela sua relevância. A presente pesquisa pautou-se nessa firmação, agrupando as respostas obtidas em categorias a partir de suas similaridades e ocorrência, fornecendo então o nome da categoria e exemplos da fala.

\section{Aspectos Éticos}

O presente estudo foi submetido inicialmente ao Comitê de Ética em Pesquisa com Seres Humanos e Animais da Universidade Estadual do Centro-Oeste e obteve parecer favorável à sua realização, número 1.111.349, o que demonstra que a mesma obedece a Resolução 466/2012.

\section{Resultados}

\section{Elaboração do programa}

A elaboração do projeto ocorreu entre o segundo semestre de 2014 e o segundo semestre de 2015. Para elaborar o Projeto Cuida-Bem foram seguidas parcialmente as indicações da literatura da área da Ciência Preventiva, sobretudo, as etapas sugeridas por Murta e Santos (2015), sendo elas citados e descritos a seguir:

Etapa 01 - Foi caracterizado por um estudo preparatório, que se refere basicamente ao levantamento de informações necessárias para que a elaboração do projeto fosse possível. Isso se deu em termos teóricos e práticos, e por esse motivo os resultados dessa etapa estão apresentados a partir dessas duas construções.

Levantamentos Teóricos: referiram-se basicamente na busca de elementos da literatura científica da área que embasassem a intervenção, como exemplo quais autores e obras, possíveis temáticas relevantes para o público-alvo definido e objetivo do projeto. Todos esses elementos são listados mais detalhadamente a seguir.

Iniciando pela subetapa proposta por Murta e Santos (2008) a respeito da definição dos objetivos do programa, é importante listar o alvo do programa e seu potencial para mudança. No projeto Cuida-Bem o alvo foi atuar como prevenção à Síndrome do Bebê Sacudido e como promoção da maior qualidade de interação entre cuidador e bebê, sendo as estratégias utilizadas para ambos o repasse de informações sobre os assuntos. O grau informativo pode aumentar o nível de conhecimento (Moreira, Nobrega, \& Silva, 2003) dos cuidadores e por isso é considerado uma estratégia de promoção e prevenção.

Outra subetapa é a Busca por estudos disponíveis. Partindo da definição de que se trataria de cuidadores e crianças, buscou-se por informações a respeito desse tema e foram encontrados materiais que enfatizavam a importância da relação cuidador-bebê, pelo fato do bebê chegar ao mundo com recursos limitados, fragilidade e nenhuma autonomia, e assim os cuidadores necessitarem reagir às suas necessidades (Bee, 2011) e, dessa forma, essa relação torna-se fundamental para o bemestar e crescimento da criança. Outras informações encontradas foram referentes às atitudes dos cuidadores que ora podem ser positivas e ora negativas, e um exemplo de atitude negativa é um abuso físico infantil, que se manifesta de diferentes formas e tendo como uma das formas de manifestação a SBS.

Com relação a subetapa avaliação de necessidades, pesquisas como as de Lopes (2013) perceberam que a SBS é pouca conhecida por cuidadores e profissionais da saúde e viu-se então a necessidade de divulgar informações sobre o mesmo.

A respeito da subetapa sobre conhecer os determinantes ambientais $e$ comportamentais da SBS, encontrou-se que atualmente se reconhece alguns fatores de risco que podem aumentar a probabilidade de ocorrência da SBS, sendo eles: 1) respectivos aos cuidadores: serem menores de 18 anos, famílias monoparentais, mães com baixo grau de escolaridade e que não fizeram o acompanhamento pré-natal, além de questões como falta de conhecimento sobre desenvolvimento infantil e padrão de choro, além de baixa tolerância à frustração; 2) respectivos ao bebê: ser menor de um ano de idade, do sexo masculino e ter nascido de 
forma prematura ou com peso abaixo da média; e 3) respectivas à situação: momentos de estresse, status socioeconômico familiar, dificuldades da gestação, entre outros (Hennes, Kini \&Palusci, 2001). No entanto, o fator que mais prevalece como desencadeante da ocorrência da SBS é o choro incontrolável do bebê, que pode provocar desequilíbrio emocional, irritação, exaustão e impotência dos cuidadores que já possuem algum fator de risco listado anteriormente (Kempe et al, 1985; LOPES 2013). Atrelado a todos esses fatores há o desconhecimento sobre os danos de se chacoalhar uma criança. É a partir deste ponto que o programa almejado teve a pretensão de agir, pois o repasse de informações é um método de mudança embasado na teoria, sendo essa uma outra subetapa citada por Murta e Santos (2008).

Assim, o método de mudança escolhido foi o de repasse de informações para cuidadores. Soejima e Bolsanello (2012) destacam que diversos programas atuam a partir dessa perspectiva e, desse modo, possibilitam aos cuidadores desenvolver estratégias de manejo de contingências em situação adequada, momento de reflexão e de contato com práticas educativas saudáveis. A aprendizagem obtida na participação da intervenção pode ser generalizada para outros espaços e relações cotidianas, evitando a existência de comportamento indesejáveis, e assim pode-se eliminar fatores de risco (Pinheiro, \&Haase 2012).

De forma específica ao tema sobre interação cuidador-bebê, maus tratos infantis e SBS, Lopes (2013, p. 16) destaca que programas sobre a SBS em formato de orientação trazem "a educação parental sobre o desenvolvimento infantil, inclusive sobre o padrão de choro do bebê", além de fornecer ensinamento da importância de regulação emocional e de como lidar com os sentimentos negativos que surgem com o choro da criança. Esses programas possuem sua efetividade comprovada (Lopes, 2013), porém, ocorrem em sua maioria em âmbito internacional, sendo que o Brasil possui apenas um trabalho que relata intervenções com essa finalidade, sendo ele o realizado por Lopes (2013). Além disso, não há na literatura nacional trabalhos que relatem experiências de programas de intervenção com cuidadores individualmente, sendo que a maioria dos trabalhos utiliza metodologia grupal. Além do mais, a maioria dos relatos não traz detalhes maiores sobre as orientações.

\section{Levantamentos Práticos: esse} momento do estudo exploratório buscou obter compreensão sobre os possíveis participantes da atividade extensionista, suas características, tomando como base a importância de identificar possíveis grupos participantes e suas características que se relacionavam direta ou indiretamente ao tema da intervenção: dados sociodemográficos, características gerais culturais, barreiras de acesso, entre outros listados por Murta et al (2015) e considerado nesta intervenção.

Sobre a subetapa escolha do públicoalvo, foi tratado como importante qual seria a acessibilidade dos participantes ao projeto. Assim, o espaço de espera para o teste da orelhinha na clínica escola de fonoaudiologia da mesma universidade facilitou tal fator, uma vez que os cuidadores vêm até a clínica e alguns deles ali permanecem por um tempo considerável, podendo então participar da intervenção no momento que seria de espera e inutilizado.

De forma geral, esse momento exigiu constante reflexão e estudo, buscas por fundamentos teóricos e metodologias de trabalho, buscas por exemplos de programas com a mesma finalidade em outros locais, além de buscas que possibilitassem conhecer um público que pudesse participar do projeto. Ainda, esta etapa buscou explorar os temas relacionados ao assunto do projeto e ajudar no amadurecimento do mesmo, no entanto, mesmo se caracterizando por uma busca exaustiva esse momento foi apenas para explorar e tornar mais conhecidas as possibilidades de execução do projeto, mas sem ainda o definir em termos de execução propriamente dita. 
Também nesta primeira etapa definiuse que o programa atuaria como Prevenção Primária, que é vista como a forma de prevenção que exige o menor gasto, e que conforme a divisão feita pela Organização Mundial da Saúde (2001) pode ser para toda a população, para um grupo que possui um maior risco de desenvolver determinada doença ou transtorno e para pessoas que já foram identificadas com risco de desenvolver tal dano.

Etapa 02: Construção da Intervenção propriamente dita: o primeiro ponto a ser considerado nessa fase é o estudo e definição sobre as estratégias da intervenção. Optou-se pela Intervenção Breve (IB), que é considerada uma abordagem objetiva, focalizada e de curta duração. A IB é também flexível, podendo ser aplicada tanto individualmente ou em grupo como em uma grande quantidade de contextos, sendo desde contextos de saúde ou sociais como escolas, comunidades, etc. Conforme França et al (2015, p. 359) "a literatura científica tem apontado evidências de eficácia da IB como estratégias de prevenção às dimensões que prejudicam a saúde mental e física dos indivíduos" e tem como objetivo principal mudar comportamento, além de auxiliar no aumento de autonomia e iniciativa.

Uma questão mais específica referente ao projeto Cuida-Bem foi que o mesmo foi coordenado por duas professoras do Departamento de Psicologia da mesma universidade onde foi realizado e foi executado por acadêmicas do mesmo curso. Todas as etapas foram realizadas pelas professoras e acadêmicas, sendo que uma etapa específica e que não é mencionada por Murta e Santos (2008) especificamente, mas, que foi realizada no projeto é a formação das alunas. Para isso houve reuniões com o objetivo de realizar leituras sobre o assunto, role play de simulação de orientações, entre outros formatos de aprendizado dos temas a serem trabalhados e também das habilidades necessárias para realizar os atendimentos aos participantes.
Além disto, buscou-se adequar o programa à realidade do público-alvo e então foi definido que a duração seria curta (aproximadamente 40 minutos) e um único encontro, para que não exigisse do participante ter que se deslocar mais de uma vez até a clínica escola e também que não despendesse de qualquer pagamento para poder participar. Esses fatores foram considerados especificamente, mas também são evidenciados na literatura (Dumka et al, 1995; Lohr et al, 2007) como preditores de adesão.

Outro ponto sobre a estratégia de intervenção refere-se aos referenciais teóricos que embasaram metodologicamente as ações do programa. Isto é, após definido o formato de atuação, foi pensado quais os temas a serem explorados, sendo que os materiais escolhidos para embasar as intervenções foram extraídos de Antunes (2011), Bee (2011), Brazelton (1995), Caminha, Soares e Kreitchmann (2011) e Lopes (2013). A partir destas leituras, foi discutido e definido os temas a serem trabalhados nas orientações, que circularem entre os seguintes tópicos: choro (tipos, função do chorar no início da vida do bebê, estratégias para lidar com o choro incessante); SBS (definição, diferença entre chacoalhar e embalar, como ocorre e como prevenir); Sono (padrões e distúrbios do sono no primeiro ano de vida); Alimentação; Comunicação; Linguagem; Interação entre o cuidador e o bebê; Rotina (importância e dicas de como implantá-la) e informações sobre Desenvolvimento Infantil. Além disso, as intervenções de orientação aos cuidadores também tiveram como embasamento teórico a literatura da Psicologia do Desenvolvimento e do referencial da Análise do Comportamento, pois como aponta Lohr et al (2007) é de extrema importância definir a abordagem teórica que guiará a elaboração e execução de um Programa de Intervenção Precoce.

A respeito da subetapa chamada de definição material para intervenção, exposta por França et al (2015) como de fundamental importância dentro do planejamento e organização de IB's, foi confeccionada uma cartilha entregue nas orientações. A cartilha 
seguiu as indicações dadas por Moreira, Nobrega e Silva (2003) a respeito de materiais educativos para uso na área da Saúde e também os apontamentos de Murta (2008) sobre materiais para intervenções psicoeducativas, respeitando as indicações quanto à necessidade de clareza e didática. $\mathrm{O}$ material foi entregue aos participantes durante a participação no projeto, nela constavam informações pontuais sobre os assuntos apresentados e discutidos na orientação, conforme apresentado na Figura 01, exposta na página a seguir.

\section{DICAS SOBRE $O$ DESENVOLVIMENTO E BEM-ESTAR DO SEU BEBË}

\section{0 que bebês de $0-6$ meses fazem?}

0 - 2 meses: reconhecem a voz e o cheiro do cuidador, dormem, mamam e choram com frequência, começam a sorrir e balbuciar, reagem a sons, podem apresentar cólicas.

2 - 4 meses' dão gritinhos, conseguem sustentar a cabeça, respondem com sons quando 0 cuidador fala, acompanham os objetos com 0 olhar e estendem as mãos para tentar pegá-los.

4 - 6 meses: conseguem se virar e sentar sem apoio, dormem períodos de sono mais longos, levam os objetos a boca, gostam de conversar emitindo sons. Por volta dos 6 meses outros alimentos podem ser ingeridos pelo bebê, além do leite.

\section{0 choro é comum nessa fase}

Os bebês choram cerca de duas a três horas por dia. Afinal, no início a única forma que possuem de se comunicar e expressar
suas necessidades é por meio do choro. Geralmente, os choros são (aㅣ) diferentes para fome, cólica ou sono. Cu Dessa forma, busque reconhecer os tipos de choro do seu bebê.

Lembre-se: os bebês são diferentes! Podem comportar-se diferente uns dos outros e em tempos diferentes.

\section{Coisas a evitar...}

- Ficar com 0 bebê quando você está preocupado ou estressado;

- As vezes é melhor deixar um pouco sozinho do que sacudir quando o choro é intenso

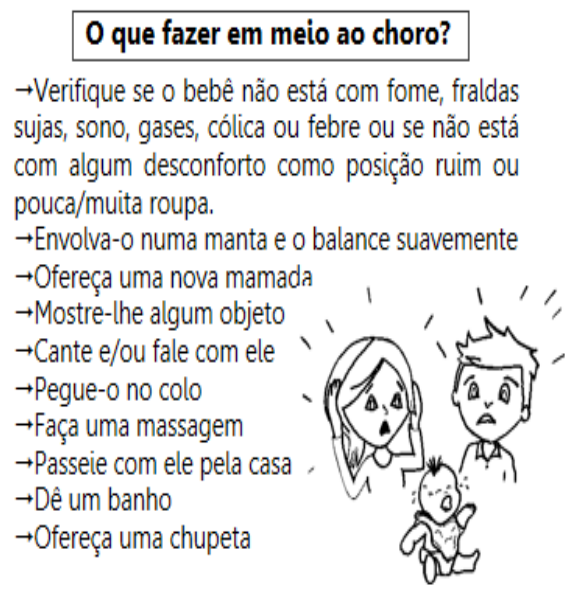

Caso tenha tentado todas as possibilidades e o choro não passou...

$\rightarrow$ Acalme-se e respire fundo

$\rightarrow$ Faça uma pausa e se afaste do barulho do choro

$\rightarrow$ Chame outro cuidador para ajudar

$\rightarrow$ Peça ajuda para parentes ou vizinhos

$\rightarrow$ Ligue para um profissional de saúde

\section{Porque não se deve chacoalhar o bebê...}

A cabeça do bebê é maior e mais pesada que 0 corpo e se balançada para frente e para trás ou para cima e para baixo de forma violenta e rápida pode gerar um impacto com consequências graves para o desenvolvimento do bebê, como:

- fraturas - hemorragias • lesões cerebrais

-vômitos •cegueira • parada cardíaca • surdez - convulsões • paralisia cerebral

Isso é chamado de Sindrome do Bebê Sacudido.

\section{Para ter uma interação positiva} comseubebê...

- Chame-o pelo nome, de forma clara

- Olhe nos olhos do bebê enquanto fala

- Fale com o seu bebê! Ele não entenderá exatamente 0 que está sendo dito, mas entenderá seu carinho direcionado a ele, seu

tom de voz e atenção.

- Crie uma rotina para ele e para você

- Observe o sono profundo do seu bebê, para ver se não há pausas prolongadas.

- Escute e repita o que o bebê fala (bá, pá)

- O embale com carinho

- Mostre para o bebê o mundo que o cerca, passeando com ele e the mostrando pessoas e objetos

- Faça da hora da amamentação um momento especial, olhe e converse com seu bebê

- Mantenha o ambiente seguro e tranquilo, com boas relaçôes familiares

- Aproveite a hora do banho para interagir, conversar e fazer massagens

\section{É IMPORTANTE:}

- Rir, conversar, cantar, abraçar e bejjar sempre - Sempre que perceber que 0 bebê teve uma conquista, o elogie, aplauda, the dê um carinho.

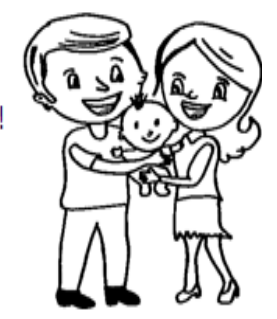

- Crie momentos de

Interação positiva com o bebê!

Faz bem para ele e para você!!

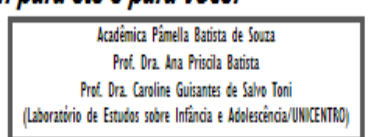

Figura 1. Cartilha elaborada pela equipe do projeto e entregue aos participantes.

Conforme Murta et al (2015) devem ser escolhidos os canais pelos quais serão ofertadas a intervenção, além de qual contexto de implementação (escola, serviços de assistência social, entre outros), o contexto escolhido para execução do projeto foi o espaço da Clínica-escola, essa questão foi mencionada e explicada na Etapa 01, pois foi quando foi estudada e analisada para poder ser definida nesta segunda etapa. 
Com relação ao canal de implementação, o programa foi divulgado por meio de cartazes e folders, que foram inicialmente distribuídos no espaço da universidade, incluindo a própria clínica escola e em seguida esses materiais foram entregues nos serviços de assistência social e saúde (públicos e privados) do município, além de uma apresentação do programa para os responsáveis por esse serviço. De forma paralela, foi criado uma fan page em uma rede social para o programa, onde constam informações a respeito dos assuntos tratados no programa e também informações sobre onde e como o programa ocorre.

Levando em consideração que para disseminá-lo era necessário um nome atrativo, curto e de fácil entendimento (questões também citadas por Dumka et al., 1995), decidiu-se pelo nome Programa "Cuida-Bem".

A subetapa de pré-testagem se deu de forma concomitante à execução do projeto e nela foram avaliados os métodos e materiais. Já a Customização ao grupo alvo sugerida por Murta e Santos (2015) se deu de forma a considerar as especificidades do grupo trabalhado, sendo a principal delas a consideração sobre a importância do uso de linguagem não rebuscada com os participantes.

Etapa 03 - esta foi a última etapa e refere-se ao Teste Piloto de intervenções preventivas e de promoção da saúde (MURTA, \&SANTOS, 2008). No caso do projeto CuidaBem o teste piloto foi realizado juntamente com a execução geral do projeto, ou seja, à medida que as intervenções ocorreram, foram discutidos em reuniões todos os desempenhos: desde o formato de atendimento, a postura e receptividade dos participantes, suas características e os assuntos que acabaram despertando mais interesse dos mesmos.

Com essas análises por meio de discussões foi observada a clareza do projeto, que mostrou adequação entre objetivo e método utilizado, além de também mostrar que possuía atratividade e viabilidade. Essas duas últimas questões foram observadas por dois motivos: referente à atratividade, os participantes eram convidados a participar do programa e um número significativo de fato aceitava, e a viabilidade foi analisada pelo fato de não exigir dos participantes qualquer investimento logístico ou financeiro e apenas disponibilidade de tempo, sendo que esse também existia uma vez que as intervenções ocorreram durante um momento de espera.

Uma reformulação total da elaboração não foi necessária, e sim adequações para sua execução futura.

\section{Avaliação dos resultados do programa}

A seguir é apresentado, em categorias, os temas das respostas, bem como fragmentos que as exemplificam, sendo que os participantes estão identificados através de números.

Antes da orientação: nesse momento apenas uma das cinco cuidadoras afirmou saber as graves consequências de chacoalhar um bebê, enquanto a maioria dos participantes $(n=4)$ alegaram não saber, porém, alguns citaram algumas noções básicas sobre os danos como "eu sei que dá arroto depois de ter mamado, mas um pouco chacoalhar, não muito" (P1) e "Dá dor no corpo ou que ele na verdade vai ficar cansado e não vai dormir bem se eu ficar chacoalhando" (P5). Ainda no momento anterior à participação no programa, todos os participantes responderem não conhecer o termo Síndrome do Bebê Sacudido, como P3 que afirma "nunca ouvi falar dessa síndrome, nem sabia que existia isso".

Antes das orientações pode-se perceber que todos os cuidadores entrevistados desconheciam tanto as consequências negativas de sacudir um bebê, quanto o termo SBS. Esse dado é bastante relevante e sobre ele, Lopes (2013) aponta que o desconhecimento e falta de informação sobre as consequências negativas do uso de punição 
física em crianças, sobretudo, as chacoalhadas fortes em bebês, é a principal responsável pela manutenção dessa prática. Como afirmam Cecconello, Antoni e Koller (2003), muitas vezes os cuidadores desconhecem as consequências graves de balançar fortemente seu bebê e associam tal ato a algo não prejudicial, ou seja, não possuem conhecimento sobre as consequências deste ato.

No entanto, notou-se que houve aumento do conhecimento dos participantes sobre sacudir um bebê, bem como sobre as estratégias para lidar com o estresse pessoal e/ou o choro do bebê e sobre o conhecimento do termo SBS, sendo esse conhecimento agrupado em diferentes assuntos:

Compreensão sobre consequências negativas do chacoalhar: "é perigoso (...) tem vários problemas que pode apresentar depois" (P1); "pode trazer sérias consequências para o desenvolvimento da criança, como cegueira" (P2); "eles ficam irritado, tem bebê que não gosta de ser chacoalhado" (P3); "futuramente o bebê vai acabar tendo algum problema e se você não souber você vai acabar você causando o problema para o seu nenê" (P4); "pode trazer muitas consequências ruins, pode ficar cego, pra aprendizagem, chega a vomita" (P5);

Compreensão entre a relação entre chacoalhar e desenvolver a síndrome: "eu entendi que sacudi o bebê pode levar né (...) a essa síndrome do bebe sacudido" (P2); "é importante (se referindo a não chacoalhar) para não causar nenhuma Síndrome para o bebê" (P4);

Chacoalhar como algo associado a brincadeira, mas que pode causar dano: "ele (marido) gosta de ficar brincando e isso pode causar alguma consequência pra criança" (P2); "vê eles sorrindo e feliz, mas que na verdade pode tá prejudicando essa brincadeira" (P5);
Sobre a importância de não realizar essa ação, as participantes verbalizaram:

"jamais faria isso (...) nunca tentaria (...) É, que é importante pra ele, pra ela, pra criança, que nunca seja sacudida " (P1); "terei mais cuidado né daqui pra frente com meu filho" (P2); "depois sabendo do que pode acontecer mais ainda que procurar não chacoalhar de maneira nenhuma (...) "nunca vou chacoalhar o meu bebê porque não quero que ela nunca tenha nada de lesão, que nunca aconteça nada com ela e deus o livre né, ela pegar por um descuido da gente, por não ter uma orientação ainda acabar prejudicando o bebê né" (P3);

Também foram obtidos dados acerca da importância de cuidadores saberem a respeito: "foi muito bom saber dessa síndrome do bebê sacudido e saber que é importante jamais chacoalhar o bebê" (P3); "Eu acho que é importante as mães saberem que não devem chacoalhar o bebê (...) "se você não estiver bem informado sobre isso você vai acabar machucando teu bebê sem saber o que você está fazendo né" (P4). Além disso, a importância de o participante da pesquisa repassar essas informações a outros cuidadores do bebê: "vou passar essa questão pro meu esposo" (P2);

Evidentemente, se percebe a ampliação dos repertórios de conhecimento dos participantes a respeito da ligação entre do estresse do cuidador com o ato de chacoalhar uma criança, a importância de criar estratégias para melhor lidar com o choro do bebê, que é o principal eliciador das chacoalhadas, conforme Lopes (2013). Todos os conhecimentos obtidos pelos participantes podem atuar como agentes de proteção aos maus-tratos infantis como também possibilitar um grau satisfatório de interação entre cuidador-bebê, atundo assim tanto como promoção de saúde e bem-estar como prevenção de maus-tratos infantis. 


\section{Conclusões}

Esse estudo buscou descrever a formulação de um programa de orientação breve a pais e cuidadores, com ênfase na interação positiva e prevenção de maus tratos, sobretudo, da Síndrome do Bebê Sacudido, bem como apresentar os principais resultados de sua implementação, por meio de uma avaliação de seus resultados qualitativos.

A respeito da elaboração do programa, notou-se que foi uma etapa que exigiu diferentes habilidades e ações das professoras e acadêmicas envolvidas, o que demonstra a importância de conhecimento técnico e cientifico para realização de ações como essas. Além disto, a elaboração se deu através de diversos e diferentes momentos, como confecção do material ilustrativo a ser utilizado, bem como levantamento do públicoalvo e suas necessidades e crenças, além do levantamento de informações importantes a serem repassados a este público. Cada momento foi de real importância e mostrou como resultado uma execução que obteve sucesso mesmo em um momento inicial. Além disto, realizar o programa descrito demonstrou que de fato o desenvolvimento infantil é afetado por diversos fatores, desde biológicos como culturais, relacionais e sociais e quanto aos fatores de ordem relacional e social, o meio familiar ganha destaque, uma vez que o é o primeiro e mais importante contexto de interação e aprendizagem da criança. Desse modo, o ambiente familiar é visto como fundamental para o desenvolvimento do ser humano. Os achados referentes a etapa de formulação demonstram que é possível - e necessário - seguir etapas citadas na literatura de referencia da área, tais indicações e orientações tão suporte para a concretização de programas de prevenção e promoção mais efetivos e estruturados.

Com relação à avaliação do programa, por meio das entrevistas, pode-se constatar que os participantes ampliaram seus conhecimentos sobre os danos de chacoalhar um bebê, bem como foram apresentados ao termo SBS. Deste modo, esta fase demonstrou que o programa atingiu seu principal objetivo: levar informações aos cuidadores. Afirma-se isso pelos resultados das entrevistas terem sido significativos no antes e depois, principalmente nas questões que competem ao ato de chacoalhar uma criança e a SBS. Assim, os resultados mostraram que a intervenção foi eficaz em propiciar conhecimento aos participantes sobre desenvolvimento infantil, interação saudável entre cuidador e bebê, além de informações sobre a SBS.

Neste sentido, pode-se afirmar que o projeto conseguiu repassar informações aos cuidadores e mudar algumas concepções. No entanto, não se pode afirmar que as concepções modificadas serão refletidas nas práticas diárias dos cuidadores. Para isso, seriam necessários mais estudos para verificar o efeito a médio e longo prazo de tal intervenção, se de fato produziu mudança de comportamento. Esses estudos envolveriam, por exemplo, pesquisas longitudinais com grupos controle e experimental e um grande número de participantes. Porém, uma possibilidade em se pensar uma possível mudança de prática dos cuidadores, a partir da mudança de suas concepções, é dada a partir do que aponta Lopes (2013), pois logo ao início da vida dos bebês os pais já sabem a respeito da Síndrome e de suas consequências e os bebês participantes do programa possuíam, em sua maioria $(80 \%)$, até dois meses de vida.

Uma das limitações do projeto foi referente à necessidade de criação de mais materiais alternativos que pudessem auxiliar nas orientações como também a ampliação dos temas para bebês maiores de um ano, pois alguns bebês de algumas participantes possuíam mais de um ano. Aponta-se também, apoiando-se na literatura da área, para a necessidade de intervir não somente com os pais, mas também com os profissionais que trabalham com crianças nos hospitais, escolas, educação infantil, e demais contextos. 
Aponta-se também, apoiando-se na literatura da área, para a necessidade de intervir não somente com os pais, mas também com os profissionais que trabalham com crianças nos hospitais, escolas, educação infantil, e demais contextos.

Além disto, como evidenciado ao longo do texto, a SBS ainda é pouco conhecida no Brasil, de forma que há poucos estudos nacionais a respeito do assunto. Neste sentido, sugere-se aprofundamento nessa temática, tanto em termos teóricos quanto de intervenções que visem levar a comunidade em geral informações a respeito de uma questão tão importante a respeito de desenvolvimento de bebês.

Por ser realizado dentro dos parâmetros da extensão universitária, o projeto foi uma possibilidade de desenvolver um elo entre a comunidade e a universidade e ao mesmo tempo de possibilitar conhecimento teórico e prático para as alunas envolvidas. Também pode possibilitar à estudantes de Psicologia contato com a temática, ou seja, foi possível oferecer o conhecimento sobre a SBS a alunas que futuramente atuarão como psicólogas em diferentes espaços, quem sabe em espaços referentes à cuidadores, crianças, etc.

Uma conclusão geral é que ao oferecer aos cuidadores essas informações, o programa atuou como prevenção, enfatizando fatores de proteção que, por sua vez, diminuem os fatores de risco. Para atuar a partir dessa perspectiva, a confecção da cartilha fez-se fundamental, pois a confecção de materiais ilustrativos em saúde pode atuar como prevenção.

Por fim, este relato de experiência reafirma a importância da extensão universitária como formato possível para realização de programas de prevenção e promoção e também espera ter evidenciado que é possível realizar programas de extensão universitários embasados cientificamente.

\section{Referências}

Antunes, C. (2011). Guia para estimulação do cérebro infantil: do nascimento aos 3 anos. 2. Ed. Petrópolis - RJ: Vozes.

Bardin, L. (2011). Análise de conteúdo. Lisboa: Edições 70.

Baumrind, D. (1966). Effects of authoritative parental control on child behavior. Child Development, Chicago, v. 37, p. 887-907.

Bee, H. (2011). A criança em desenvolvimento. Porto Alegre: Artes Medicas.

Berlinguer, G. (1994). Bioética da prevenção. Rev Bioética, 02, p. 117-122.

Brazelton, T.B. (1995). O Grande Livro da Criança. Lisboa: Editorial Presença.

Brasil. (1990). Lei $n^{o} 8.069$ de 13 de julho de 1990. Dispõe sobre o Estatuto da Criança e do Adolescente e dá outras providências. Brasília, 13 de julho de 1990, Fernando Collor.

(2001). Ministério da Saúde. Secretaria de Políticas de Saúde. Violência intrafamiliar: orientações para prática em serviço / Secretaria de Políticas de Saúde. Brasília: Ministério da Saúde.

Caminha, R. M.; Soares, T.; Kreitchmann, R.S. (2011). Intervenções Precoces: promovendo resiliência e saúde mental. In: Caminha, M. G.; Caminha, R. M.; et. al. Intervenções e treinamento de cuidadores na clínica infantil. Porto Alegre: Sinopsys, p. 31-79.

Campos, C.J.G. (2004). Método de Análise de Conteúdo: ferramenta para a análise de dados qualitativos no campo da saúde. Rev Bras Enferm, Brasília (DF) set/out;57(5), p. 611-4.

Cardoso, A.C.A et al. (2003). Recomendações para o atendimento de crianças e adolescentes vítimas de violência física (maus tratos). Rev Pediatria Moderna. Vol. XXXIX. No 9. Set.

Carmo, P. H.B., Alvarenga, P. (2012). Práticas educativas coercitivas de mães de diferentes níveis socioeconômicos. Rev Estudos de Psicologia. 17(2), maio-agosto, p. 191-197. 
Case M.E.; Graham, M.A.; Handy, T.C.; Jentzen, J.M.; Monteleone, J.A. (2001). Position paper on fatal abusive head injuries in infants and young children. $\mathrm{Am} \mathrm{J}$ Forensic Med Pathol. 2001; 22, p. 112-122.

Cecconello, A.M, Antoni, C, Koller, S.H. (2003). Práticas Educativas, Estilos Parentais e Abuso Físico no Contexto Familiar. Rev Psicologia em Estudo, Maringá, v. 8, p. 45-54.

Dumka, L. e et al. (1995). Using research and theory to develop prevention programs for high-risk families. Family relations, p. 7886.

Especialista ensina a identificar a razão do choro do bebê. 2015. Recuperado em 10 de setembro de 2015, de http://tvuol.uol.com.br/video/especialistaensina-a-identificar-a-razao-do-choro-dobebe-04020d99346ae0995326.

Foley, S.; Kova'cs, Z.; Rose, J.; Lamb, R.; Tolliday, F.; Simons-Coghill, M.; Stephens, A. Scheiber, D.; Toma, A. Asbo'th, K. Kassai, T. Agathonos, H. Lopes, N.R.L.; Williams, L.C.A.; Sahin, F.; Tasar, A.; Sarten, T. (2013). International collaboration on prevention of shaken baby syndrome - an ongoing project/intervention. Paediatrics and International Child Health. v. 33 N.4

Gil, M.S.C.A, Oliveira, T.P, Sousa, N.M. (2012). Desenvolvimento Humano. In: Hubner, M.M.C, Moreira, M.B (Org). Fundamentos de Psicologia: Temas Clássicos da Psicologia sob a Ótica da Análise do Comportamento. Rio de Janeiro: Guanabara Koogan.

Graça, P.R.M., Teixeira,M. L. C., Lopes, S.C.G., Serrano, A.M.S.P.H., Campos, A.R.S (2010). O Momento da Avaliação na Intervenção Precoce: O Envolvimento da Família Estudo das Qualidades Psicométricas do Asq-2 dos 30 aos 60 Meses. Rev. Bras. Ed. Esp., Marília, v.16, n.2, Mai.-Ago, p.177-196.

Hennes H, Kini N, Palusci VJ. (2001). The epidemiology, clinical characteristics and public health implications of Shaken Baby Syndrome. In: Lazoritz S, Palusci VJ, editors. The Shaken Baby Syndrome: A multidisciplinary approach. Binghamton: The Haworth Maltreatment \& Trauma Press; 2001, p. 19-40.

Kempe, C.R., Denver, F.N.S., Cincinnati, B.T.S., Droegemueller, W., Silver, H.K (1985). The Battered-Child Sindrome. Child Abuse \& Neglect, vol 9, p. 143 - 154.

Lohr, S. S.; Pereira, A.C.S.; Andrade, A.L.M.; Kirchner, L.F. (2007). Avaliação de Programas Preventivos: relatos de experiência. Rev Psicologia em Estudo, v.12, n.3, set/dez, p. 641-649.

Lopes, N.R.L (2013. Trauma Craniano Violento: Conhecimento Parental e Avaliação de Material Informativo. Dissertação (Mestrado em Psicologia) Universidade Federal de São Carlos. São Carlos: UFSCar,. $130 \mathrm{p}$.

Maia, J.M.D; Williams, L.C.A. (2005). Fatores de Risco e Fatores de Proteção ao desenvolvimento infantil: uma revisão da área. Rev Temas em Psicologia, vol 13, $\mathrm{n}^{\circ}$ 2, p. 91-103.

Marinho, M. L. (2000). A intervenção clínica comportamental com famílias. In E. F. M. Silvares (Org.), Estudos de caso em psicologia clínica comportamental infantil. Campinas: Papirus.

Moreira, M. F.; Nóbrega, M. M. L.; Silva, M. I. T. (2003). Comunicação escrita: contribuição para a elaboração de material educativo em saúde. Rev. Bras. Enferm., Brasília (DF), 56(2), p. 184-188.

Não sacuda seu bebê (Síndrome do bebe sacudido). (2009). Realizador LAPREV (Laboratório de Analise e Prevenção a Violência). Local: São Carlos - São Paulo. (3:40 min), son, color. Recuperado em 07 de julho de 2015, de

https://www.youtube.com/watch?v=o0vAS $\underline{\mathrm{BX} 8 \mathrm{CQ} 0}$

Organização Mundial da Saúde. (2001). Prevenção e Promoção em Saúde Mental. Genebra: OMS.

Papalia, D.E.; Feldman, R.D (2013). Desenvolvimento Humano. 12 Ed. PortoAlegre: AMGH.

Pelaez, M., Novak, G (2004). Child and adolescente develoment: A Behavioral 
Systems Approach. London: Sage

Publications.

Pereira, A.C.S., Dittrich, A. (2007). O

conceito de Prevenção para o behaviorismo radical: em busca de práticas preventivas de maior sucesso. In: STARLING, R.R. Sobre Comportamento e Cognição: temas aplicados. Santo André-SP: ESETec Editores Associados.

Pinheiro, M.I.S., Haase, V.G. (2012).

Treinamento de Cuidadores: Programas de Intervenção. In: Baptista, M.K, Teodoro, M.LM. Psicologia de Família: Teoria, Avaliação e Intervenção. Porto-Alegre: Artmed.

Plenário do Conselho Nacional de Saúde (2012). Aprova as seguintes diretrizes e normas regulamentadoras de pesquisas envolvendo seres humanos. Resolução $n^{o}$ 466, de 12 de dezembro de 2012.

Soejima, C.S., Bolsanello, M. A. (2012).

Programa de intervenção e atenção com bebês na Educação Infantil. Educar em Revista, Ed. UFPR, Curitiba, PR, n. 43, p. 65-79, jan./mar.

Weber, L.N.D. Interações entre Família e Desenvolvimento. (2008). In: Weber, L.N.D (Org) Família e Desenvolvimento: Visões Interdisciplinares. Curitiba: Jurua. Williams, L. C. A., Habigzang, L. F (2014). Crianças e Adolescentes vítimas de violência: Prevenção, avaliação e intervenção. Curitiba: Juruá. direto), graduada em Psicologia pela Universidade Federal do Paraná. Professora da Universidade Estadual do Centro-oeste, IratiPR.

Dados sobre as autoras:

- Pâmella Batista de Souza é Mestranda em Psicologia (Universidade Federal de Santa Catarina) e Psicóloga (Universidade Estadual do Centro-Oeste).

- Ana Priscila Batista é Doutora em Educação pela UFPR, mestre em Psicologia pela USP, psicóloga pela UEM. Professora do Departamento de Psicologia da Universidade Estadual do Centro-Oeste.

- Caroline Guisantes de Salvo Toni é Doutora em Psicologia Clínica pela USP (doutorado 